\title{
LARGE SCALE EXPERIMENTS ON FARMS OF HEAVING BUOYS TO INVESTIGATE WAKE DIMENSIONS, NEAR-FIELD AND FAR-FIELD EFFECTS
}

\author{
Vasiliki Stratigaki ${ }^{1}$, Peter Troch ${ }^{1}$, Timothy Stallard ${ }^{2}$, Jens Peter Kofoed ${ }^{3}$, Michel Benoit ${ }^{4}$, \\ Giovanni Mattarollo ${ }^{4}$, Aurélien Babarit ${ }^{5}$, David Forehand ${ }^{6}$, Matthew Folley ${ }^{7}$
}

\begin{abstract}
The shrinking reserves of fossil fuels in combination with the increasing energy demand have enhanced the interest in renewable energy sources, including wave energy. In order to extract a considerable amount of wave power, large numbers of Wave Energy Converters will have to be arranged in arrays or farms using a particular geometrical layout. The operational behaviour of a single device may have a positive or negative effect on the power absorption of the neighbouring WECs in the farm (near-field effects). Moreover, as a result of the interaction between the WECs within a farm, the overall power absorption and the wave climate in the lee of the WECs is modified, which may influence neighbouring farms, other users in the sea or even the coastline (far-field effects). Several numerical studies on large WEC arrays have already been performed, but large scale experimental studies on near-field and far-field wake effects of large WEC arrays are not available in literature. Within the HYDRALAB IV European programme, the research project WECwakes has been introduced to perform large scale experiments in the Shallow Water Wave Basin of DHI, in Denmark, on large arrays of point absorbers for different layout configurations and inter-WEC spacings. The aim is to validate and further develop the applied numerical methods, as well as to optimize the geometrical layout of WEC arrays for real applications.
\end{abstract}

Keywords: Wave Energy Converters; WEC; WEC arrays; WEC farms; WECwakes; wake effects; renewable energy, large scale experiments, wave energy; HYDRALAB IV

\section{INTRODUCTION}

The increasing energy demand, the need to reduce greenhouse gas emissions and the shrinking reserves of fossil fuels have all enhanced the interest in sustainable and renewable energy sources, including wave energy. In order to extract a considerable amount of wave power, large numbers of Wave Energy Converters (abbreviated as WECs) will have to be arranged in arrays or farms using a particular geometrical layout.

The operational behaviour of a single device may have a positive or negative effect on the power absorption of the neighbouring WECs in the farm (so-called near-field effects). As a result of the interaction between the WECs within a farm, the overall power absorption is affected. Finally, the wave height behind a large farm of WECs is reduced and this reduction may influence neighbouring farms, other users in the sea or even the coastline (so-called far-field effects). Two main types of wave energy converters are typically distinguished: type (i) which includes absorption and radiation (a floating body or oscillating water column) and type (ii) which includes only absorption (a fixed or slack moored overtopping device that captures the overtopped waves in a basin above sea level) (Stratigaki et al. 2011).

\section{WAKE EFFECTS - IMPORTANCE OF GEOMETRICAL LAYOUT AND IN-BETWEEN DISTANCES OF WEC ARRAYS}

In Fig. 1, the importance of the geometrical lay-out of a WEC arrays is illustrated. Using the wave propagation model MILDwave (Troch 1998, Stratigaki and Troch 2012) wake effects have been modelled behind wave energy converters, by using a sponge layer technique developed at Ghent University. In Fig. 1 wakes can be easily visualized for an example of devices of the overtopping type, while results are presented in terms of the disturbance coefficient $k_{d}\left(=H_{s} / H_{s G B}\right.$, with $H_{s}$ the local significant wave height and $\mathrm{H}_{\mathrm{sGB}}$ the wave height at the wave generation boundary). Waves are propagating from the bottom to the top of Fig. 1, while the 'white squares' simulate generic wave

\footnotetext{
${ }^{1}$ Department of Civil Engineering, Ghent University, Technologiepark 904, Zwijnaarde, B-9052, Belgium

${ }^{2}$ School of Mechanical Aerospace and Civil Engineering, University of Manchester, Manchester, M13 9PL, United Kingdom

${ }^{3}$ Department of Civil Engineering, Wave Energy Research Group, Aalborg University, Sohngaardsholmsvej 57, Aalborg, DK-9000, Denmark

${ }^{4}$ Laboratoire Saint-Venant, EDF - Recherche et Développement, 6 quai Watier BP 49, Chatou, 78401, France

${ }^{5}$ Ocean Energy and Ocean Waves Group, LHEAA Lab, Ecole Centrale de Nantes - CNRS UMR6598, Nantes, France

${ }^{6}$ Institute for Energy Systems, Institute for Energy Systems, The University of Edinburgh, The King's Buildings, Edinburgh, EH9 3JL, ZIP/Zone, United Kingdom

${ }^{7}$ Marine Renewables Research Group, Queen's University Belfast, Belfast, BT9 5AG, United Kingdom
} 
energy converters with a certain power absorption. The wake in the lee of the WEC array is clearly visible, with areas of reduced $k_{d}$ values, represented by variable contour lines. When the geometrical layout and the number of devices of the WEC array changes (Fig. 1a-b-c), the wake behind the WEC array changes as well.

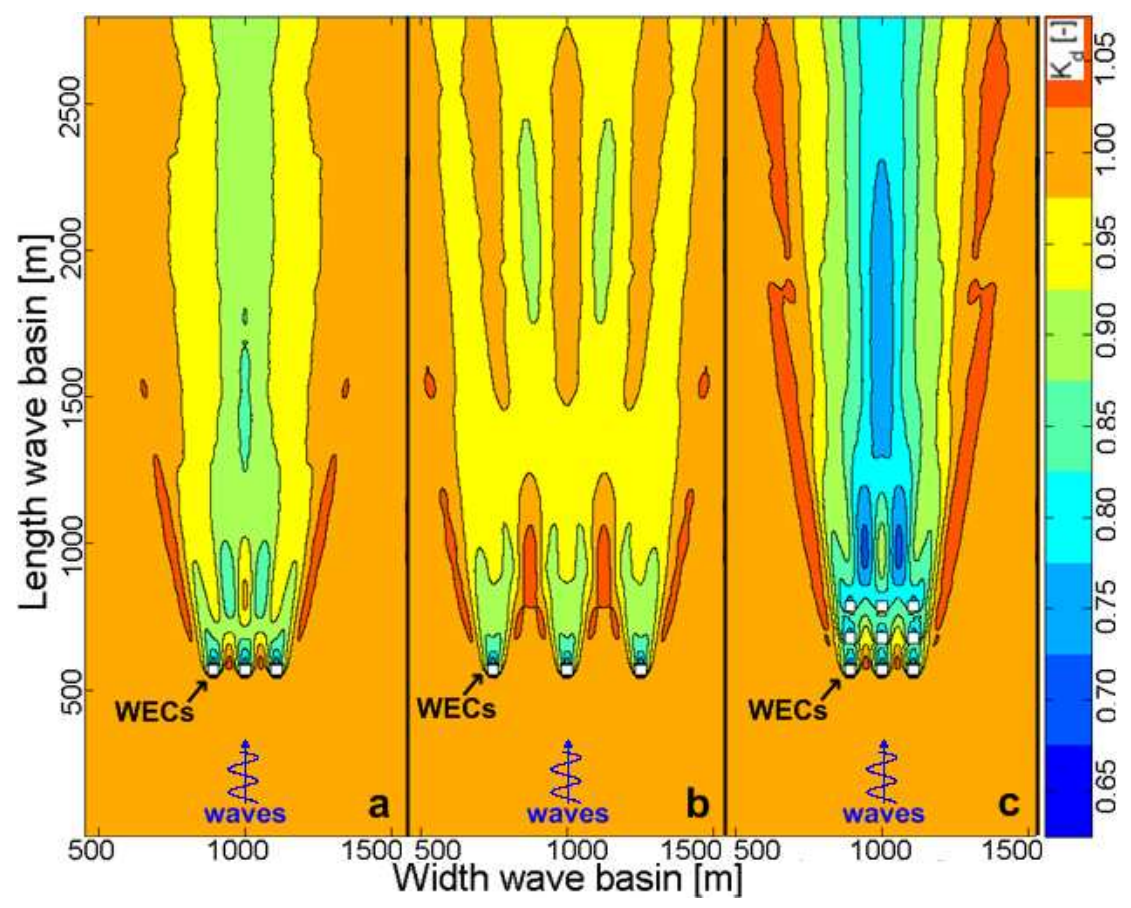

Figure 1. Wake effects behind WEC-farms (WECs of the overtopping type). Wave height reduction behind the WECs is visualized by the reduction of the disturbance coefficients $k_{d}$ (=local $H_{s} /$ incident $\left.H_{s, i}\right)$. WEC-farms of: a) 3 WECs, b) 3 WECs with larger inter-WEC distances, c) 9 WECs (Troch et al. 2010).

Figures 1.a and 1.b, where a row of 3 generic WECs of the overtopping type is simulated, give a clear idea of the importance of the in-between distances for an array of wave energy converters. The resulting wake e.g. when the inter-WEC spacing is smaller (Fig. 1.a) is much different compared to the wake behind an array with the same number of WECs but much larger spacing between the devices (Fig. 1.b).

\section{NUMERICAL MODELLING OF WEC ARRAYS}

Several numerical methods have been employed to analyse the response of WECs (Folley et al. 2012). Several numerical studies on large WEC arrays have already been performed (e.g. Troch et al. 2010, Child 2011, Borgarino et al. 2012). Boundary Element Methods (BEM) based on potential flow (e.g. Aquaplus (Delhommeau 1987), WAMIT (www.wamit.com)) have been used intensively to study the hydrodynamic interaction of multiple oscillating bodies (near-field effects) for small computational domains. To study far-field effects, for example to analyse coastal impact, a much larger computational domain is required.

Wave propagation models are generally employed in which the WEC is represented as a porous structure which extracts a specific quantity of wave power, exhibiting a certain amount of reflection, transmission and absorption of the incoming waves. The spectral wave propagation model, SWAN (Booij et al. 2007) has been used to study the change of the wave climate caused by the installation of a farm of WECs $20 \mathrm{~km}$ off the north coast of Cornwall, UK (Millar et al. 2006). In (Venugopal and Smith 2007) an array of 5 bottom mounted, fixed WECs has been modelled in a nonlinear Boussinesq wave model (MIKE21 (www.dhigroup.com)).

Moreover, wake effects in the lee of a single WEC and multiple WECs (WEC types i and ii) have been studied (Beels et al. 2010, Troch et al. 2010) by using the mild-slope wave propagation model MILDwave developed by Troch (Troch 1998, Stratigaki and Troch 2012) and by applying a sponge layer technique, by which the redistribution of wave power within and behind each farm is studied in 
detail (Fig. 1). Nevertheless, no experimental studies concerning wake effects of large WEC-farms (near-field and far-field effects) are available in literature, which are required for verification of the previously mentioned numerical methods.

\section{PHYSICAL MODELLING WITH INDIVIDUAL OR PAIRS OF WECS}

Individual or pairs of WECs have been experimentally studied, while nowadays a small number of single prototypes of WECs are being tested at sea. In 1979, Budal et al. reported measurements of the free-response amplitude and absorption of a (rigidly connected) pair of hemispherical ended floats with a diameter of $15 \mathrm{~cm}$. The device mass and damping were specified to attain a resonant response with the incident wave and good agreement was observed with the point absorber theory. At a similar time, a series of tests was conducted by Count and Jefferys (1980) at the University of Edinburgh. Measurements of the interaction factor of a linear array of both two and ten devices at different spacings were in reasonable agreement with point absorber predictions.

Moreover, in the eighties, Vantorre (1985) performed numerical and experimental tests on a 2-body point absorber system. In 2005, Vantorre et al. compared numerical (using Aquaplus (Delhommeau 1987)) and experimental results of the hydraulic performance of a heaving point absorber, followed by tests on a single buoy by De Backer (2009). At the Ecole Centrale de Nantes the SEAREV device has been extensively studied both numerically and experimentally. Validations of (non-)linear models are presented in Durand et al. (2007), Gilloteaux et al. (2007) and Babarit et al. (2009). In 2008, Payne et al. compared BEM simulations of the sloped IPS buoy with experimental tests, carried out in the Edinburgh Curved Tank.

\section{PHYSICAL MODELLING ON SMALL WEC ARRAYS}

In contrast to the quantity of numerical analysis of WEC arrays and the large body of experimental work concerning individual or pair of WECs, only a very limited number of experimental studies of WEC arrays have been published. In the last decade, experimental measurements of the response of the Wave Star device have been conducted and have led to construction and testing of a prototype at an offshore site near the location of Hanstholm, in Denmark (Marquis et al. 2010).

Experimental measurements of the response and power output of small arrays of closely-spaced heaving floats were reported in Stallard et al. (2008) and Weller et al. (2009) respectively. In Alexandre et al. (2009) the change of significant wave height and wave spectra due to energy extraction by arrays of 5 and 10 heaving floats has been measured. Finally, within the Supergen programme large-scale tests ( 5 floats of $0.6 \mathrm{~m}$ diameter) have been conducted with a preliminary results analysis by Ashton et al. (2009).

\section{NEED FOR LARGE SCALE EXPERIMENTS ON WEC ARRAYS}

From the previous sections it is clear that very few small scale experiments have been performed dealing with waves and WEC-farms. Moreover, there are no experimental studies performed for studying wake effects of large WEC-farms (far-field effects) for which large wave basins are necessary. The growing number of numerical studies of wake effects caused by WEC-farms need, though, to be verified by experimental data, which will allow the further development of the applied numerical methods. Those numerical methods, used for modelling of single wave energy converters or WEC arrays, have been recently reported and evaluated in Folley et al. (2012).

Finally, the results of testing various WEC-farm configurations will lead to the optimization of the farm lay-outs for real applications. The following important questions have to be answered:

- what is the positive or negative effect on power absorption using large numbers of WECs?

- what are the dimensions and the impact of the WEC wakes?

- what is the effect on power absorption of changing inter-WEC distances?

Therefore, the present research project has been introduced in order to perform innovative large scale experiments with large WEC farms with the objective to cover the gap of experimental studies in the literature and to determine near-field and far-field effects from large farms of Wave Energy Converters. For producing such an experimental data set a large experimental facility is essential.

In this research project, the wake effects by farms composed of devices of the oscillating type (i) (point absorbers) will be investigated for several farm configurations and wave conditions. A point absorber typically consists of a float with horizontal dimensions that are small compared to the incident wave lengths. The float is designed to oscillate along a vertical axis only and can thus be modelled as a 
single degree of freedom system. Energy is absorbed by damping the buoy motion and converted into electricity by a generator.

\section{PLANNING OF LARGE SCALE EXPERIMENTS ON WEC-FARMS}

Within the HYDRALAB IV European programme, access to the Shallow Water Wave Basin of DHI (Denmark) has been granted for the present research. The acronym of this research project is 'WECwakes'. Main objective is to determine experimentally near-field and far-field wake effects from large WEC-farms composed of devices of the oscillating type (point absorbers) using different farm configurations and wave conditions. The WECs have been developed and thoroughly tested at the wave flume of Ghent University (Fig. 2) and the wave basin of the Queen's University of Belfast (QML Queen's University Marine Laboratory) (Fig. 3). The point absorber-WECs have been tuned for optimum power absorption for several wave conditions. Their Power Take-off system (PTO), which is a simple friction-break (Fig. 2, left), shows very good operational behaviour with very good repeatability of the obtained results of power absorption.
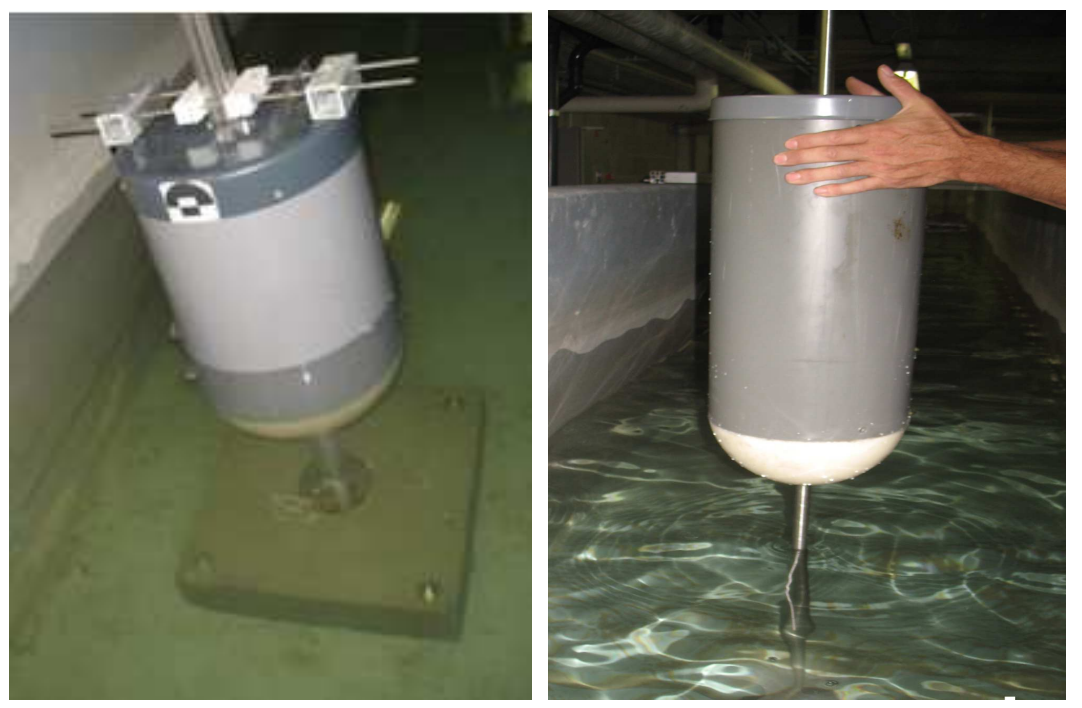

Figure 2. The developed generic point absorber WEC during experiments in the wave flume of Ghent University, Belgium.

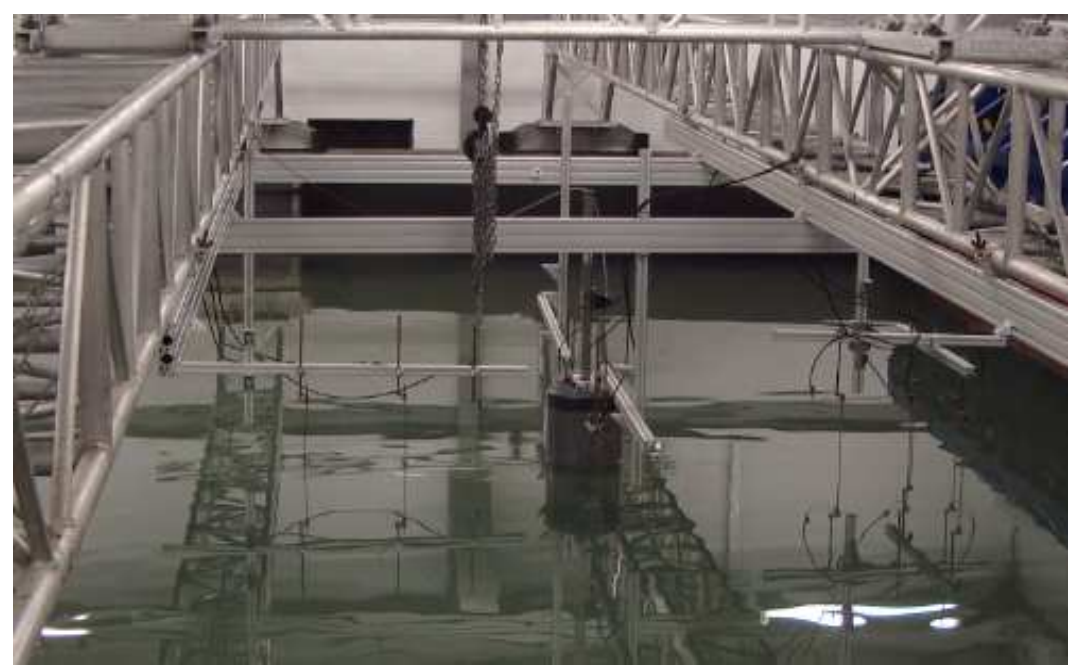

Figure 3. The developed generic point absorber WEC during experiments in the wave basin of Queen's University Belfast, Northern Ireland, UK. 


\section{RESEARCH OBJECTIVES}

The main objective of the present research is to improve the understanding of the wake effects of wave energy converters (i.e. the change of wave conditions) due to energy extraction by WEC-farms. Knowledge of both the behaviour of a single WEC affecting its neighbours (near-field effects) and the shadow effects behind a large farm (far-field effects), which can play a significant role to the performance of neighbouring farms, to other activities/users in the sea or the beach morphology at the coastline, are important in the design of a farm of WECs.

In order to achieve the main objective, the following more detailed objectives have been defined:

1. To understand the behaviour of a 'farm' of WECs under several wave conditions.

2. To determine the near-field effects between the WECs.

3. To determine the far-field effects: to measure and detect the dimensions of WEC-farm wakes and their impact (e.g. reduction on wave height caused by WECs in the lee of the WEC-farms, etc).

4. To quantify the effect on power production by:

(i) changing the distances between the WECs in a farm,

(ii) changing the number of the WECs in a farm, and,

(iii) modifying the WEC farm geometrical layout.

5. To compare data with results from the established point absorber theory.

6. To provide experimental data for validation of numerical models, used by partners of the research team and by researchers worldwide (Folley et al. 2012) for wave propagation through WEC farms: i.e. phase resolving models (e.g. MILDwave (Troch 1998, Stratigaki and Troch 2012), ARTEMIS (Aelbrecht 1997), phase averaging models (e.g. SWAN (Booij et al. 2007), TOMAWAC (Benoit et al. 1996) and Boundary Element Methods based on potential flow (e.g. Aquaplus (Delhommeau 1987), WAMIT (www.wamit.com)).

7. To study the modification of near shore wave conditions due to wave energy extraction at an offshore location.

\section{METHODOLOGY AND TECHNICAL DETAILS OF THE EXPERIMENTS}

Several idealised wave and wave-device interaction problems are considered (diffraction, radiation and absorption) for different WEC configurations and wave conditions. Generic wave energy converters of the oscillation type (floating bodies) are used during the experiments, providing experimental data suitable for studies of the interaction between both widely and closely spaced point absorbers (different WEC farm configurations) and for validation purposes of WEC-farm studies.

Regarding the wave conditions, the experiments are based on theoretical arguments for waves propagating through a WEC-farm and the dependence of their transformation on geometrical and operational properties of the WECs which compose the farm. Hence the methodology includes regular, irregular and short-crested waves propagating through WEC-farms. The (peak) wave periods that have been chosen correspond to the (peak) period at the natural frequency of the floating body $\left(\mathrm{T}_{\mathrm{p}, \mathrm{n}}\right)$, representing the worst case for the numerical methods, and (peak) wave periods representing operational conditions.

Initially, the reflection, transmission and absorption of a single WEC is experimentally determined. Finally, more WECs are gradually added to the initial WEC array, which eventually form WEC farms with different lay-outs and inter-WEC spacing. In this way, the effects on the wave field and on the overall power production by using multiple WECs are investigated.

The number of WECs, their lay-out and the distances between them are of great importance for the resulting wakes behind the WEC-farms, and also for the interaction between the WECs and the effect on their efficiency regarding wave power absorption.

Finally, the large scale experiments aim at the acquisition of the following data:

1. The primary output is wave height in the vicinity of the WEC-farm and inshore of the WEC-farm.

2. Measurements of undisturbed wave field - at a large number of points in the vicinity of the WEC array and at the positions of the wave energy devices.

3. Measurements of wave field due to various incident wave conditions - at a large number of points in the vicinity of the WEC array and within the wake behind the WEC array (at specific locations behind the WECs).

4. Measurements of wave field in front of the WEC-farms providing data for the incident wave field. 
CHARACTERISTICS OF THE SCALE MODEL

As the maximum number of WECs of a farm is large, the individual WECs are simple regarding their construction and their operational behaviour. A generic point absorber (buoy) has been developed with a total height of $61 \mathrm{~cm}$, a hemispherical bottom and a cylindrical PVC prefabricated upper part (Fig. 2). The buoy's draft is $31.5 \mathrm{~cm}$, equal to its diameter, with a total mass of $20.545 \mathrm{~kg}$ (Stratigaki et al. 2012).

The WEC has only one degree of freedom: it is restricted to heave motion along a vertical, square, hollow stainless steel axis that is anchored in a concrete square cement base. The axis passes through a slightly larger shaft bearing inside the wave energy device, which continues over the total height of the buoy to avoid water infiltration. The square form of the axis hinders rotation. The movement of the buoy in the horizontal plane, due to the margin between axis and shaft bearing, is prevented by two PTFE bearings at the top and bottom of the buoy, chosen for the low friction coefficient on steel.

Moreover, the power take-off (abbreviated as PTO) is simulated by a mechanical brake, through which the extracted energy is lost by friction. The PTO consists of 4 springs, exerting a normal force on two PTFE-blocks on top of the buoy, which are pressed against the axis (Fig. 2, left).

\section{PREPARATION OF THE LARGE SCALE EXPERIMENTS}

A series of experiments with the developed point absorber WEC model (tests with single devices) has been performed aiming at the optimization of the WEC models before the final experiments within the HYDRALAB IV granted access to the large scale laboratory facilities of DHI.

The preparation of the HYDRALAB IV large scale experiments is organized in three levels:

- with a single device at the wave flume of Ghent University (Belgium) for structural testing of the WEC model. This flume is $1.0 \mathrm{~m}$ wide, $30 \mathrm{~m}$ long and has a water depth of $0.70 \mathrm{~m}$.

- with a single device at the wave basin of the Queens Marine Laboratory (Queen's University Belfast - Northern Ireland, UK) to test the hydrodynamic response of the WEC model. This wave basin is $15 \mathrm{~m}$ wide and $17 \mathrm{~m}$ long, with a water depth of $0.61 \mathrm{~m}$.

- with small arrays of point absorber WEC models which will be soon carried out in the large wave flume of Flanders Hydraulics Research, in Antwerp (Belgium), to test interaction between WEC models. This flume is $4.0 \mathrm{~m}$ wide, $70 \mathrm{~m}$ long and has a water depth of $1.40 \mathrm{~m}$.

\section{DEVELOPING THE POINT ABSORBER WEC MODEL}

So far, for the preparation of the large scale experiments in the large scale facilities of DHI in Denmark, tests have been performed in the wave flume of Ghent University (Fig. 2) and the wave basin of Queen's University Belfast (Fig. 3).

The model is being tested under the action of regular and irregular long- and short-crested waves, for four different test cases:

- without the presence of the buoy.

- with the buoy as fixed obstacle.

- $\quad$ with the buoy but no damping applied through the PTO.

- with the buoy and damping applied through the PTO.

The model is being tested for representative wave conditions of several European Countries (e.g. Belgium, France, Germany, Portugal, Denmark, The Netherlands).

\section{Experiments in the 2-D wave flume of Ghent University, Belgium}

The first series of experiments has been carried out in the large wave flume of the laboratory at Ghent University, which has a width of $1.0 \mathrm{~m}$ and a water depth of $0.7 \mathrm{~m}$. Those experiments aim at the structural testing of the model (rigidity of vertical axis, base stability for different installation techniques, internal friction issues, etc.) and the optimization of the measuring techniques for the vertical motion of buoy (using camera, potentiometer or LVDT), as well as for the horizontal motion of the vertical axis of the WEC (using a camera).

The horizontal movement of the vertical axis of the WEC is limited, indicating a sufficient bending stiffness, with the best results achieved when the base is moored, while the influence of the measuring techniques used for the buoy motion has been determined. In this experimental setup, the reflection from the sidewalls does not allow investigation of the buoy motion and the water surface elevations, as the buoy diameter is large compared to the width of the wave flume. 


\section{Experiments in the 3-D wave basin of Queen's University Belfast, Northern Ireland, UK}

The same series of tests has been performed in the wave basin of Queen's University Belfast, which is $15 \mathrm{~m}$ wide and $17 \mathrm{~m}$ long, with a water depth of $0.61 \mathrm{~m}$. The experiments in the wave basin aim at the tuning of the power take-off system (abbreviated as PTO-system) for the wave conditions of the large scale experiments in DHI, concentrating on optimum power absorption.

Moreover, the influence of the WEC model on the wave field and its vertical motion have been investigated, which were not possible in the wave flume. Measurements of the vertical motion of the buoy using a potentiometer and of the water surface elevation using a network of resistive wave gauges have been taken.

During the tests in the wave basin, the repeatability of the (un)damped buoy motion has been confirmed, indicating the effectiveness of the developed PTO-system. Optimum power absorption has been achieved.

\section{SUMMARY}

Within the HYDRALAB IV European programme, the research project WECwakes has been introduced to perform large scale experiments in the Shallow Water Wave Basin of DHI, in Denmark, on large arrays of point absorbers, for different layout configurations and inter-WEC spacings. The aim is to study near-field and far-field wake effects of large WEC farms and to validate and further develop the applied numerical methods, as well as to optimize the geometrical layout of WEC arrays for real applications.

Within the frame of the present research a generic point absorber WEC model has been developed, which finally will be used in large numbers during the experiments in the wave basin of DHI for studying wake effects of WEC farms.

So far, several research steps have been already achieved and other are about to start soon.

The construction of the WEC model at the workshop of Ghent University (Belgium) has been completed. The model is a simple and easily reproducible structure which can be produced in large numbers.

The structural testing of the WEC model has been completed, e.g. stability tests regarding the installation techniques used for the buoy. This testing took place at the wave flume of Ghent University in order to deal with any structural problems of the WEC model. As a result of this series of experiments, the buoy has been optimized, including installation and measurement techniques.

Further, the testing of the hydrodynamic response of a single WEC model has been completed at the wave basin of Queen's University Belfast. Those tests have shown the efficiency and repeatability of the developed power take-off system of the WEC model. During the tests at the wave basin of QML in Belfast the buoy has been tuned for optimal damping force.

Soon, a new series of experiments for small arrays of WEC models will take place in the wave flume of Flanders Hydraulics Research. Those tests aim at the investigation of the interaction between WEC models and will be the last series of preparatory tests before the start of the planned large scale experiments.

Finally, tests will be performed in the 3-D shallow water wave basin of DHI, in Denmark, with the intention to study wake effects and device-device interaction for large wave energy converter arrays with different WEC numbers and lay-out configurations.

\section{ACKNOWLEDGMENTS}

This study is conducted within the frame of HYDRALAB IV, EU project.

The construction of the WEC models at the workshop of Ghent University has been funded by the Research Foundation Flanders, Belgium.

Moreover, the first author would like to acknowledge her Ph.D. funding grant by the Research Foundation Flanders, Belgium (Fonds voor Wetenschappelijk Onderzoek Vlaanderen, FWO).

\section{REFERENCES}

Aelbrecht, D. 1997. ARTEMIS 3.0: a finite element model for predicting wave agitation in coastal areas \& harbours including dissipation, Transactions on the Built Enviroment, vol.27, Wit Press, ISSN 1743-3509.

Alexandre, A., T. Stallard, and P.K. Stansby. 2009. Transformation of Wave Spectra across a Line of Wave Devices. Proceedings of the $8^{\text {th }}$ European Wave and Tidal Energy Conference, Uppsala, Sweden. 
Ashton, I., L. Johanning, and B. Linfoot. 2009. Measurement of the Effect of Power Absorption in the Lee of a Wave Energy Converter, Proceedings of the $28^{\text {th }}$ International Conference on Offshore Mechanics \& Arctic Engineering, Honolulu, Hawaii, OMAE 2009, vol. OMAE2009-79793.

Babarit A., H. Mouslim, A. Clement, and P. Laporte-Weywada. 2009. On the numerical modelling of the non-linear behaviour of a wave energy converter. Proceedings of the $28^{\text {th }}$ International Conference on Offshore Mechanics \& Arctic Engineering, Honolulu, Hawaii, OMAE 2009.

Beels, C., P. Troch, G. De Backer, M. Vantorre, and J. De Rouck. 2010. Numerical implementation \& sensitivity analysis of a wave energy converter in a time-dependent mild-slope equation model, Coastal Engineering, Vol. 57(5), pp. 471-492.

Benoit M., F. Marcos, and F. Becq. 1996. Development of a third generation shallow-water wave model with unstructured spatial meshing. Proceedings of the $25^{\text {th }}$ International Conference on Coastal Engineering, ASCE.

Borgarino, B., A. Babarit, and P. Ferrant. 2012. Impact of wave interactions effects on energy absorption in large arrays of wave energy converters. Ocean Engineering, 41, 79-88.

Budal, K., J. Falnes, A. Kyllingstad, and G. Oltedal. 1979. Experiments with point absorbers in regular waves. Proceedings of the $1^{\text {st }}$ Symposium on Wave Energy Utilization, pp. 253-282, Gothenburg.Sweden.

Child, B.F.M. 2011. On the configuration of arrays of floating wave energy converters. Ph.D, Thesis, Edingburgh University.

Count, B.M. and E.R. Jefferys. 1980. Wave power, the primary interface. Proceedings $13^{\text {th }}$ Symposium for Naval Hydrodynamics, 8, 1-10.

De Backer, G.. 2009. Hydrodynamic Design Optimization of wave energy converters consisting of heaving point absorbers, $P h D$ thesis, Department of Civil Engineering, Ghent University, Belgium.

Delhommeau G. 1987. Le problème de diffraction radiation et de résistance de vagues : étude théorique et résolution numérique par la méthode des singularités, Thèse Ecole Nationale Supérieure de Mécanique, Nantes.

Durand M., A. Babarit, B. Pettinotti, O. Quillard, J. Toularastel, and A. Clement. 2007. Experimental validation of the performances of the SEAREV wave energy converter with real time latching control. Proceedings of the $7^{\text {th }}$ European Wave and Tidal Energy Conference, Portugal.

Folley, M., A. Babarit, L. O' Boyle, B. Child, D. Forehand, K. Silverthorne, J. Spinneken, V. Stratigaki, and P. Troch. 2012. A review of numerical modeling of wave energy converter arrays, Proceedings of the $31^{\text {st }}$ International Conference on Offshore Mechanics \& Arctic Engineering, Rio de Janeiro, Brazil.

Gilloteaux J.C., A. Babarit, G. Ducrozet, M. Durand, and A. Clement. 2007. A nonlinear potential model to predict large-amplitude motions: application to the SEAREV wave energy converter. Proceedings of the $26^{\text {th }}$ International Conference on Offshore Mechanics \& Arctic Engineering, USA.

Marquis, L., M. Kramer, and P. Frigaard. 2010. First Power Production figures from the Wave Star Roshage Wave Energy Converter. Proceedings of the $3^{\text {rd }}$ International Conference on Ocean Energy (ICOE), Bilbao.

MIKE21,DHI-Water.Environment.Health, http://www.dhigroup.com.

Millar, D.L., H.C.M. Smith, and D.E. Reeve. 2006. Modelling analysis of the sensitivity of shoreline change to a wave farm. Ocean Engineering, 34, 884-901.

Payne G., J. Taylor, T. Bruce, and P. Parkin. 2008. Assessment of boundary-element method for modelling a free-floating sloped wave energy device. Part 2: Exp. validation. Ocean Engineering, 35: 342-357.

Stallard T., P.K. Stansby, A. Williamson. 2008. An experimental study of closely spaced point absorber arrays. Proceedings of the $18^{\text {th }}$ International Offshore \& Polar Engineering Conference, Canada.

Booij, N., I.J.G. Haagsma, L.H. Holthuijsen, A.T.M.M. Kieftenburg, R.C. Ris, A.J. van der Westhuysen, and M. Zijlema. 2007. SWAN cycle III version 40.51AB User Manual.

Stratigaki, V., P. Troch, T. Stallard, J.P. Kofoed, M. Benoit, G. Mattarollo, A. Babarit, D. Forehand, and M. Folley. 2011. Large scale experiments on wave energy converter farms to study the nearfield effects between the converters and the far-field effects on other users in the coastal area. HYDRALAB IV, Research report.

Stratigaki, V., and P. Troch. 2012. A short introduction to the wave propagation model MILDwave. MILDwave manual, Department of Civil Engineering, Ghent University. 
Stratigaki, V., P. Troch, M. Vantorre, and M. Folley. 2012. Development of a point absorber Wave Energy Converter for investigation of wake effects in large scale experiments. Proceedings of the $4^{\text {th }}$ International Conference on the Application of Physical Modelling to Port and Coastal Protection (Coastlab12), Ghent, Belgium.

Troch, P., C. Beels, J. De Rouck, and G. De Backer. 2010. Wake effects behind a farm of wave energy converters for irregular long-crested and short-crested waves. Proceedings of the International Conference on Coastal Engineering, No. 32(2010), Shanghai, China. Paper \#: waves.22. Retrieved from http://journals.tdl.org/ICCE/.

Troch, P. 1998. MILDwave - A numerical model for propagation and transformation of linear water waves. Internal Report, Department of Civil Engineering, Ghent University.

Vantorre M. 1985. Third-order potential theory for determining the hydrodynamic forces on axisymmetric floating and submerged bodies in a forced periodic heave motion. $\mathrm{PhD}$ thesis, Ghent University.

Vantorre M., R. Banasiak, R. Verhoeven. 2004. Modelling of hydraulic performance and wave energy extraction by a point absorber in heave. Applied Ocean Research; 26:61-72.

Venugopal, V. and G.H. Smith. 2007. Wave climate investigation for an array of wave power devices. Proceedings of the $7^{\text {th }}$ European Wave and Tidal Energy Conference, Porto.

WAMIT, User Manual. http://www.wamit.com/manual.htm.

Weller S., T. Stallard, P.K. Stansby. 2009. Experimental measurements of irregular wave interaction factors in closely spaced arrays. Proceedings of the $8^{\text {th }}$ European Wave and Tidal Energy Conference, Sweden. 